\title{
Measuring ecological impact of water consumption by bioethanol using life cycle impact assessment
}

\author{
Yi-Wen Chiu • Sangwon Suh • Stephan Pfister • \\ Stefanie Hellweg • Annette Koehler
}

\begin{abstract}
Purpose Though the development of biofuel has attracted numerous studies for quantifying potential water demand applying life cycle thinking, the impacts of biofuel water consumption still remain unknown. In this study, we aimed to quantify ecological impact associated with corn-based bioethanol water consumption in Minnesota in responding to different refinery expansion scenarios by applying a life cycle impact assessment method.

Methods This ecological damage assessment method for quantifying water consumption impacts was proposed by Pfister et al. in 2009 (Environ Sci Technol 43: 4098-4104, 2009) using an impact characterization factor integrating terrestrial net primary production and precipitation. In this study, we derived the spatially explicit eco-damage characterization factors for 81 watersheds in Minnesota and compiled location-specific water consumption data for all current and planned bioethanol production facilities and feedstock production. The ecological damage caused by
\end{abstract}

Y.-W. Chiu

Water Resources Science, University of Minnesota,

9700 South Cass Avenue, Building 362,

Lemont, IL 60439, USA

S. Suh $(\square)$

Bren School of Environmental Science and Management, 3422 Bren Hall, University of California,

Santa Barbara, CA 93106, USA

e-mail: suh@bren.ucsb.edu

S. Pfister $\cdot$ S. Hellweg $\cdot$ A. Koehler

ETH Zurich, Institute of Environmental Engineering,

8093 Zurich, Switzerland bioethanol production $\left(\Delta \mathrm{EQ}_{\mathrm{EtOH}}\right.$ in $\left.\mathrm{m}^{2} \cdot \mathrm{yr}\right)$ was then calculated on both watershed and refinery-plant levels. Additional refinery expansion scenarios were established for testing the effectiveness in changing $\triangle \mathrm{EQ}_{\mathrm{EtOH}}$.

Results and discussion The results show that ecological impact $\Delta \mathrm{EQ}_{\mathrm{EtOH}}$ varied by more than a factor of 3 between watersheds. Minnesota consumed 40 billion liters of water to produce 2.3 billion liters of ethanol as of 2007 (17 L water per liter of ethanol). The geographical distribution of $\Delta \mathrm{EQ}_{\mathrm{EtOH}}$ was shown to be uneven with a cluster of highimpact regions around the center of the state. The planned refinery expansion is expected to increase the state's corn ethanol production capacity by $75 \%$ and $\Delta \mathrm{EQ}_{\mathrm{EtOH}}$ by $65 \%$. However, strategically locating the planned expansion in the low-impact areas is expected to minimize the increases in $\triangle \mathrm{EQ}_{\mathrm{EtOH}}$ down to $19 \%$ from $65 \%$.

Conclusions The scenario analysis shows that strategically sourcing corn from low-impact regions can result in significantly less water use impact compared to a baseline scenario. The results indicate that employing the water consumption impact assessment can provide additional insights in policy making. The environmental impacts related to the change of plant infrastructure and agricultural practices associated with the development of the renewable energy industry should be considered as well for identifying the most sustainable alternatives.

Keywords Biofuel · Ethanol - Water use impact - Water consumption · Watershed

\section{Introduction}

Biofuels are a rapidly growing class of water-intensive products whose production is largely influenced by the 
formulation of government policy. In the USA, the Energy Policy Act sets a target of 28 billion liters of renewable fuel to be domestically produced by the year 2012. As of 2007, this target had already been outpaced (Renewable Fuels Association 2008) and, under the current Renewable Fuel Standard, the rapid increase in renewable fuel production is expected to reach 136 billion liters by 2022 , or $11 \%$ of that year's projected national liquid fuel demand (Environmental Protection Agency 2008b, a).

The sharp increase in biofuel production, particularly that of corn-based bioethanol, in recent years has raised widespread concerns over its environmental costs (Bringezu et al. 2009; King and Webber 2008; National Research Council. 2008; Varghese 2007). For instance, a recent report from the United Nations Environmental Programme highlighted the potential environmental impacts associated with 118 to 508 million hectares of additional cropland necessary to meet the future global biofuel needs (Bringezu et al. 2009).

While the primary focus of previous studies has been on the net greenhouse gas impacts of biofuel production, growing attention is now being paid to the water withdrawn and consumed throughout the life cycle of biofuel products. A report from the National Research Council warned that the production of a liter of biofuel may require as much as $780 \mathrm{~L}$ of water for irrigation (National Research Council. 2008). A study by King and Webber which estimated the life-cycle water intensity of biofuels found that approximately $500 \mathrm{~L}$ of water are consumed per liter of irrigated corn ethanol produced in the USA (King and Webber 2008). Estimates of biofuel's water requirements calculated in previous studies range from 250 to over $1,600 \mathrm{~L}$ of water withdrawal or consumption per liter of ethanol (National Research Council. 2008; Varghese 2007; de Fraiture et al. 2008; Gerbens-Leenes et al. 2009; King and Webber 2008; Romanow 2007; Mishra and Yeh 2011; Scown et al. 2011).

Chiu et al. questioned the relevance of single value estimates for ethanol's water consumption intensity (Chiu et al. 2009). Analyzing detailed state-level survey data on corn irrigation in the USA, Chiu et al. reported that bioethanol's water intensity can range from 5 to over 2,000 L of water per liter of ethanol depending upon where the feedstock is sourced (Chiu et al. 2009). The study also found that ethanol production in the USA doubled between 2005 and 2008, while total irrigated water and process water requirement for ethanol more than tripled during the same period due mainly to the expansion of corn cultivation in semi-arid regions that require more extensive irrigation (Chiu et al. 2009).

These studies primarily focused on the quantity of water consumption or withdrawals in biofuel production without considering the location of water extraction and the impact to the local environment associated with water consumption or withdrawal. Furthermore, in most of the studies, the distinction between water withdrawals and water consump- tion is not explicitly made (Bayart et al. 2010; Koehler 2008; Pfister et al. 2009). As a result, a liter of water withdrawal has been implicitly assumed to have the same environmental impact regardless of the unique characteristics associated with the location where it is withdrawn and regardless of the actual share of consumptive loss.

Recognizing the limitations of using such a simplistic measure of total water use quantity, methods have been developed to evaluate the various environmental implications of different types of water withdrawals and consumption under the framework of Life Cycle Impact Assessment (LCIA) (Frischknecht 2005; Milà i Canals et al. 2009; Pfister et al. 2009). There are two notable LCIA methods for characterization of water use impacts recently reported. These methods address the two main "areas of protection" in life cycle assessment (LCA) affected by water consumption, namely ecosystem quality and freshwater resources.

The method of Milà i Canals et al. (2009) quantifies the freshwater ecosystem impact using an ecological water stress indicator as a characterization factor. This indicator is based upon the fraction of anthropogenic water withdrawals from a river basin from the amount of renewable water resources available from the same basin after subtracting the theoretical environmental water requirements. In contrast, the method of Pfister et al. (2009) expresses ecosystem damages as spatially explicit fraction of net primary production that is limited by water availability.

The LCIA approaches proposed by Milà i Canals et al. (2009) and Pfister et al. (2009) take one step further compared to those approaches based mainly on water quantity (Gerbens-Leenes et al. 2009; Hoekstra et al. 2011; Falkenmark and Rockström 2004) in two respects: First, the LCIA approaches take regionally specific factors into account when quantifying water consumption impact, which is generally lacking in other methods. Second, LCIA approaches do not include precipitation input to or degraded water output from agricultural land, which are termed as "green water" and "gray water," respectively, while other approaches do (Gerbens-Leenes et al. 2009; Hoekstra et al. 2011; Falkenmark and Rockström 2004). Green water and gray water from agricultural land are often associated with nutrient runoff and agrochemical releases (Hoekstra et al. 2011). In LCIA, such impacts are quantified under other well-established impact categories, such as eutrophication and toxic impacts; including them to account for such impacts would therefore lead to a double counting. Unlike ecological footprint method, LCIA approaches for water impact assessment specifically aim to quantify environmental impacts associated with water consumption. Due to the lack of data, ecological footprint method assumes a uniform yield rate across all freshwater resources (Ewing et al. 2010) and does not distinguish the environmental consequences caused by different water consumption patterns. 
In this study, we aim to demonstrate how incorporating water impact assessment using a LCIA approach can support ethanol production planning in order to reduce ecological impacts. We quantified the ecological impact of irrigation and process water consumption in corn-based ethanol production in Minnesota considering the geographic variation in production sites and corn supply. We employed the regionally explicit LCIA methodology of Pfister et al. (2009) using high-resolution spatial data. The results were applied to identify potential alternative locations for planned expansion of biofuel production aiming to reduce water useassociated environmental impacts. We excluded the indirect land use in this analysis, while recognizing its importance, as methodological consensus for handling indirect land use has yet to be reached (Fargione et al. 2008; Kim and Dale 2005). Indirect land use is only one of the many consequences of large-scale biofuel production, and increase in biofuel production is not the only driver of global land use change. In addition, by examining agricultural data published by the U.S. Department of Agriculture (2010), Minnesota's corn production is marginally correlated more with yield (correlation index, 0.98) than harvested acreage (0.88) from 1960 to 2010 . Corn production and yield during the same period of time have increased by $309 \%$ and $228 \%$, respectively, whereas corn harvested area has only increased by $25 \%$. Therefore, considering the fact that assessing indirect land use requires modeling all potential consequences of biofuel production and all drivers associated with land use change, land use effect should be left for future study.

\section{Methods and data}

Due to the regional disparities in climate, soil characteristics, vegetation composition, and the availability of water, the impact of water consumption varies significantly between regions. The amount of water required to produce crops and its associated impacts can therefore vary widely depending upon the location where the crops are cultivated and where water is consumed.

Thus, spatially explicit information on the quantity of water consumption and its impact on the environment are crucial in characterizing bioethanol's water-consumption impact. In LCA terminology, the former constitutes a regional water-consumption life cycle inventory (LCI), and the latter does a regional LCIA model for water consumption. The following section elaborates on the derivation of spatially explicit information on quantifying corn ethanol water consumption from corn growing to each liter of ethanol produced in a refinery, and calculating its impacts in Minnesota using an watershed-level ecological characterization factor.

\subsection{Facility-specific water consumption}

In this study, water consumption is defined as use of water by humans that results in an alteration of natural water flow by redirecting water into a different watershed or a source other than where it was originally withdrawn (Solley et al. 1998). As water cycles, part of the water consumed may return to the original source through precipitation, percolation, and groundwater recharge. However, the amount of water that returns to the original water body after consumptive uses is generally minor (Mohamed et al. 2005), and even if it returns back to the original source, this amount is made at least temporally unavailable to the surrounding ecosystem potentially causing adverse impacts. Consumptive water use in bioethanol production thereby includes evaporative water loss from ethanol plants through cooling systems as well as shares of the irrigation water lost through evapotranspiration, both of which have been found to be the major paths of water consumption in previous studies (Mubako and Lant 2008; Wu et al. 2009; Gerbens-Leenes et al. 2009; GAO 2009; National Research Council 2008).

In Minnesota, a total of 81 watersheds are distinguished by applying the U.S. Geological Survey eight-digit hydrological unit code (MNDNR 2008a), of which 69 produce corn. In the USA, more than $80 \%$ of corn supply is produced within a 64-km radius of the ethanol facilities (Shapouri et al. 2003). Corn feedstock for ethanol production generally does not travel very far, unless the conversion facility is located in an area where corn feedstock demand exceeds corn production from the region (e.g., in the case of California). In order to derive the corn field acreage in each watershed required to supply each ethanol conversion facility, we assumed that each plant in Minnesota purchases corn from the closest cultivation area possible (see Table S1 and S2, Electronic supplementary material; Shapouri et al. 2003). Mapping the nameplate capacity and location data for each ethanol conversion facility (Nebraska Energy Office 2011; Renewable Fuels Association 2008) with detailed corn yield and production data by county (U.S. Department of Agriculture 2010; U.S. Department of Agriculture 2004), we derived the required radius of corn purchasing area including corn acreage for each conversion facility to meet its ethanol production capacity. We used a ratio of $2.4 \mathrm{~kg}$ of corn for $1 \mathrm{~L}$ of ethanol as conversion efficiency of dry mills based on available references (Patzek 2006; Mishra and Yeh 2011). For each identified corn field, irrigation water requirements were calculated using crop-specific irrigation withdrawal data derived from the Water Appropriations Permit Program (WAPP) of the Minnesota Department of Natural Resources (MNDNR 2008b).

To determine the ratio of consumptive water use from irrigation withdrawals, an average corn evapotranspiration 
rate for Minnesota was computed using the crop water demand approach (see Electronic supplementary material). The result showed that an average share of $73 \%$ of the irrigation water withdrawals is subject to evapotranspiration with minimal geographical variation in Minnesota $(\mathrm{SD}=$ 0.03). Therefore, it is acceptable to apply an aggregated irrigation efficiency of $73 \%$ in this study. To account for process-related water consumption, we applied facilityspecific data from WAPP to quantify water consumption supporting the ethanol production process (MNDNR 2008b) ranging from 2.7 to $7.6 \mathrm{~L}$ water per liter of ethanol (see SI).

\subsection{Characterizing the water consumption-related environmental impact}

For this study, we focus on ecosystem damage as water useassociated human health impacts are less relevant for the USA (Pfister et al. 2009). Pfister et al. proposed a characterization factor for ecosystem quality $\left(\mathrm{CF}_{\mathrm{EQ}}\right)$ using the ratio between water-limited terrestrial net primary production $\left(\mathrm{NPP}_{\text {wat-lim }}\right)$ estimated by Nemani et al. (2003) and precipitation $(P)$ of a region (Pfister et al. 2009). Characterization factors are provided at a $0.5^{\circ}$ grid cell resolution with a global coverage, which is well suited to the spatial resolution of the current study. Here, ecosystem damage associated with ethanol production $\left(\Delta \mathrm{EQ}_{\mathrm{EtOH}}\right)$ was computed for all 81 watersheds in Minnesota expressing the damage magnitude as ecologically degraded area where loss in NPP occurs:

$$
\begin{aligned}
\Delta \mathrm{EQ}_{\mathrm{EtOH}} & =\mathrm{CF}_{\mathrm{EQ}} \times \mathrm{WC}_{\mathrm{EtOH}} \\
& =\frac{\mathrm{NPP}_{\mathrm{wat}-\mathrm{lim}}}{P} \times \mathrm{WC}_{\mathrm{EtOH}}
\end{aligned}
$$

where $\mathrm{CF}_{\mathrm{EQ}}\left(\mathrm{m}^{2} \cdot \mathrm{yrm}^{-3}\right.$, square meter-year per cubic meter of water consumption) is the ecosystem damage factor representing the ecosystem degradation $\triangle \mathrm{EQ}_{\mathrm{EtOH}}$ $\left(\mathrm{m}^{2} \cdot \mathrm{yr}\right.$, square meter-year) caused by every cubic meter of water consumed for ethanol production $\left(\mathrm{WC}_{\mathrm{EtOH}}\right.$, cubic meter). $\mathrm{CF}_{\mathrm{EQ}}$ is equivalent to the ratio of water-limited net

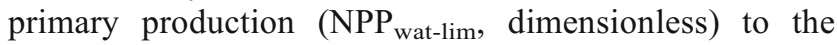
historical normal annual precipitation $P$ (meter per year) in every watershed of the study area. See Pfister et al. (2009) for details on the methodology shown in Eq. (1).

Using values of $\mathrm{NPP}_{\text {wat-lim }}$ from Nemani et al. (2003) together with Minnesota's local precipitation records (Minnesota Climatology Working Group 2010), results show that $\mathrm{CF}_{\mathrm{EQ}}$ values of the 81 watersheds range from 0.11 to $0.37 \mathrm{~m}^{2}$.per year per cubic meter of water consumption. The $\mathrm{CF}_{\mathrm{EQ}}$ values generally decrease from the west to the east Minnesota (see Table S2 and Fig. S2 in Electronic supplementary material). This trend is mainly driven by climate characteristics such as lower precipitation and higher temperature as well as higher vulnerability of $\mathrm{NPP}_{\text {wat-lim }}$ regarding water shortage in the west Minnesota region (see Fig. S2). To understand how the ecological damage $\Delta \mathrm{EQ}_{\mathrm{EtOH}}$ responds to the changes in key parameters, a sensitivity analysis was conducted employing Monte Carlo simulation (see Electronic supplementary material).

\subsection{Scenarios analysis for expansion of bioethanol production}

A number of scenarios were developed to investigate the long-term effect of strategically locating bioethanol conversion facilities and sourcing corn feedstock from regions with different water-consumption impacts (e.g., in the western Minnesota region). As of 2007, there were six additional ethanol conversion facilities planned in Minnesota, and two out of the 15 existing facilities were planning for capacity expansion (Minnesota Pollution Control Agency 2007). The new installations and capacity expansions are expected to increase the state's corn ethanol production capacity by nearly $70 \%$ from 2,590 million to 4,370 million liters. As corn for ethanol contributes a relatively minor portion of Minnesota's total corn production (19\%), strategically locating a new ethanol conversion facility in or sourcing corn feedstock from a low-impact region only shifts the burden to other corn uses such as feed for livestock without creating a positive net effect at the system level. However, a multitude of such decisions in concert may influence a region's corn supply-demand balance encouraging additional supply from the region through such developments as improved yield. Improving corn yield in water-abundant areas coupled with reduced corn production in water-limited areas could potentially avoid additional water stress on ecosystems.

In order to test the possible long-term effects of using corn feedstock from regions with low water consumptionrelated impact, we developed three what-if scenarios for the amount of ethanol that will be produced through new installations and capacity expansions. These scenarios encompass:

- Baseline scenario: corn is sourced from the vicinity of the planned locations;

- Best case scenario: corn is sourced from the corn-growing watersheds with least water-consumption impact; and

- Worst-case scenario: corn is sourced from the corngrowing watersheds with largest water-consumption impact.

In the baseline scenario, we assumed that ethanol conversion facilities source their corn feedstock from the 
nearby area using the approach introduced in Section 2.1. In the best case scenario, the new installations and capacity expansions are located in the watersheds with lowest waterconsumption impact which they also obtain their corn from, without cross-watershed corn acquisition as in the baseline scenario. We excluded the watersheds that produce less than $1,000 \mathrm{t}$ of corn per year in order to maintain a realistic minimum capacity of the ethanol conversion plants. We further constrained the maximum share of corn supply to ethanol production facilities in a given watershed to $50 \%$ of corn production in 2007 in order to fulfill other corn demands within the respective regions. In the worst-case scenario, we assumed that the new installations and capacity expansions are located in the watersheds with highest water-consumption impact. The constraints of minimum corn production and maximum share of corn supply for ethanol production as described above were also applied in the worst-case scenario.

\section{Results}

The ecological impact was analyzed from a facility-based and watershed-based perspective. In the facility-based analysis, irrigation water consumed for corn cultivation was allocated to the bioethanol facility sourcing corn from the respective regions. In the watershed-based analysis, the total water consumption from both irrigation and bioethanol processing actually occurring in a watershed was evaluated.

\subsection{Water consumption and its ecosystem impact} in bioethanol production

The overall analysis of freshwater consumption shows that approximately 40 billion liters of water were consumed to produce about 2.3 billion liters of bioethanol in Minnesota in 2007 (Fig. 1a). This figure equates to an average water consumption of $17 \mathrm{~L}$ per liter of bioethanol produced $\left(\mathrm{LL}^{-1}\right)$. Using U.S. state average data, a previous study calculating water consumption arrived at a value of $19 \mathrm{LL}^{-1}$ for the state of Minnesota (Chiu et al. 2009). Within Minnesota, however, there are significant variations in water consumption per unit of bioethanol production between regions. The facility-based analysis indicates that the amount of water consumed per liter of bioethanol declines significantly from central to southern Minnesota. The production of bioethanol consumes as much as 3 to $181 \mathrm{LL}^{-1}$ of water if it is produced in the central region, of which the watersheds exhibit significant variation in the share of irrigation in total water consumption $(3-7,100 \%)$. In southern regions, on the other hand, process water and irrigation equally contribute to overall water consumption of 3 to $8 \mathrm{LL}^{-1}$ (see Fig. 1a).
Notably, results from watershed-based and facility-based calculations may exhibit some differences (Table S5, Electronic supplementary material). For example, a highcapacity ethanol plant situated in a low corn production watershed would have to source additional corn from nearby watersheds in order to satisfy the facility's demand. Thus, a corn-growing watershed without having any in situ plant would still observe an ecological impact greater than zero due to the corn-sourcing scheme. The watersheds with the highest $\mathrm{WC}_{\mathrm{EtOH}}$ as indicated in Fig. 1a are influenced by intensive irrigation, low corn yield rates, and to a significant extent by supporting nearby ethanol plants located in adjacent watersheds. As for the facility-based $\triangle \mathrm{EQ}_{\mathrm{EtOH}}$, it accounts for the ecological impact of an ethanol plant on its corn-sourcing watersheds along with the impact associated with local process water consumption. The difference in watershed- and facility-based results reveals the importance of differentiating resource- and product-based approaches in assessing consumptive water use impacts.

Following the trends of freshwater consumption, facilityspecific $\Delta \mathrm{EQ}_{\mathrm{EtOH}}$ ranges from 0.001 to $0.044 \mathrm{~m}^{2} \cdot \mathrm{yrL}^{-1}$ of bioethanol $\left(\mathrm{m}^{2} \cdot \mathrm{yr}\right.$ per liter) with an average of $0.005 \mathrm{~m}^{2} \cdot \mathrm{yrL}^{-1}$ in Minnesota indicating a spread of almost a factor of 50 . Considering the approximate total ecosystem damage of $2.47 \mathrm{~m}^{2} \cdot \mathrm{yrL}^{-1}$ for U.S. corn-based bioethanol (excluding damage caused by water consumption) (Frischknecht 2005; Goedkoop and Spriensma 2000) (see Electronic supplementary material for the background of the calculation), ecological damage caused by ethanol water consumption in Minnesota represents only a minor contribution. The majority of ecological impacts are attributed to land use ( $96 \%$ of the total) rather than ecotoxicity, acidification/eutrophication, or water consumption.

Geographically, a cluster of bioethanol plants inducing rather high water-related ecosystem damage is located in central Minnesota (see Fig. 1b) in both watershed-based and facility-based analyses. However, in this region, irrigation water is still the primary cause of $\Delta \mathrm{EQ}_{\mathrm{EtOH}}$, whereas its impacts on the southern region are relatively small.

\subsection{Scenario analysis for future bioethanol production}

The scenario analysis shows that strategically locating the planned expansion of bioethanol production into regions with the lowest water-consumption impacts can achieve a substantial reduction in overall ecological impact. The planned expansion under the baseline scenario is expected to increase Minnesota's bioethanol production capacity by $75 \%$ from 2.3 billion to 4.0 billion liters. This increase is anticipated to consume about $57 \%$ or 23 billion liters of additional water, which elevates the state's total water consumption by bioethanol to 63 billion liters (baseline scenario). Such an expansion is expected to result in a $65 \%$ 
a

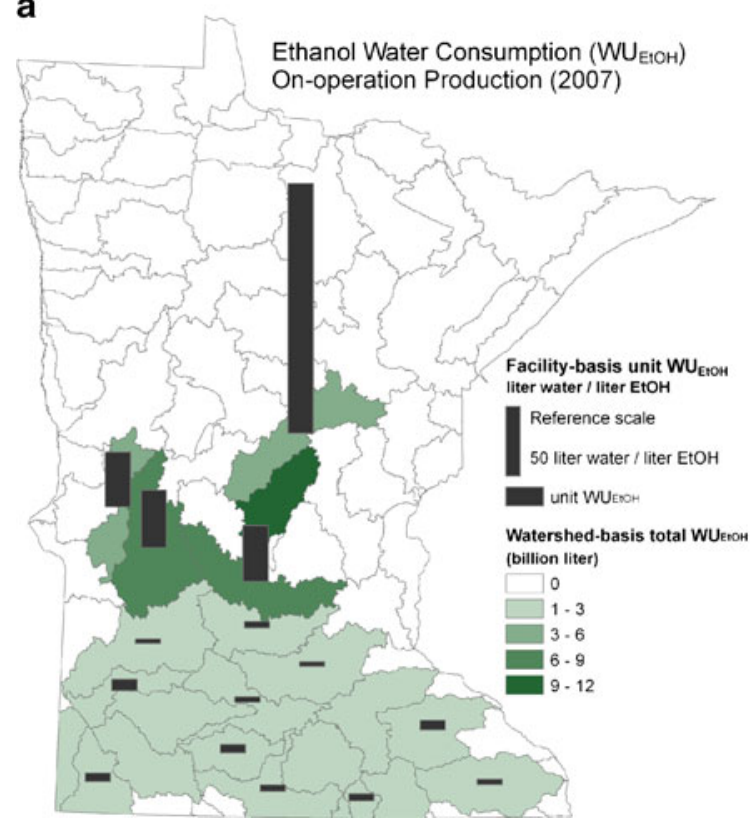

Fig. 1 a Consumptive water use for bioethanol production in Minnesota including both irrigation and process water consumption to meet nameplate capacity in 2007. The bar location indicates watersheds with at least one bioethanol conversion facility. Background colors represent the total amount of consumptive water use of all facilities within each watershed. b Water consumption-associated impact on ecosystem quality caused by bioethanol production in

increase in ecosystem damage caused by water consumption from 11 million to 18 million square meters per year of degraded area (Table 1).

By shifting the planned capacity expansion to the areas with lowest water-consumption impact, however, consumptive water use and its related ecosystem impact would increase by $17 \%$ and $19 \%$, respectively, a $46 \%$ improvement in reducing ecological impact compared with the baseline scenario. The worst-case scenario, in contrast, significantly increases the amount of consumptive water use by an average of $180 \%$ and almost triples the magnitude of total ecological impact (Fig. 2). b

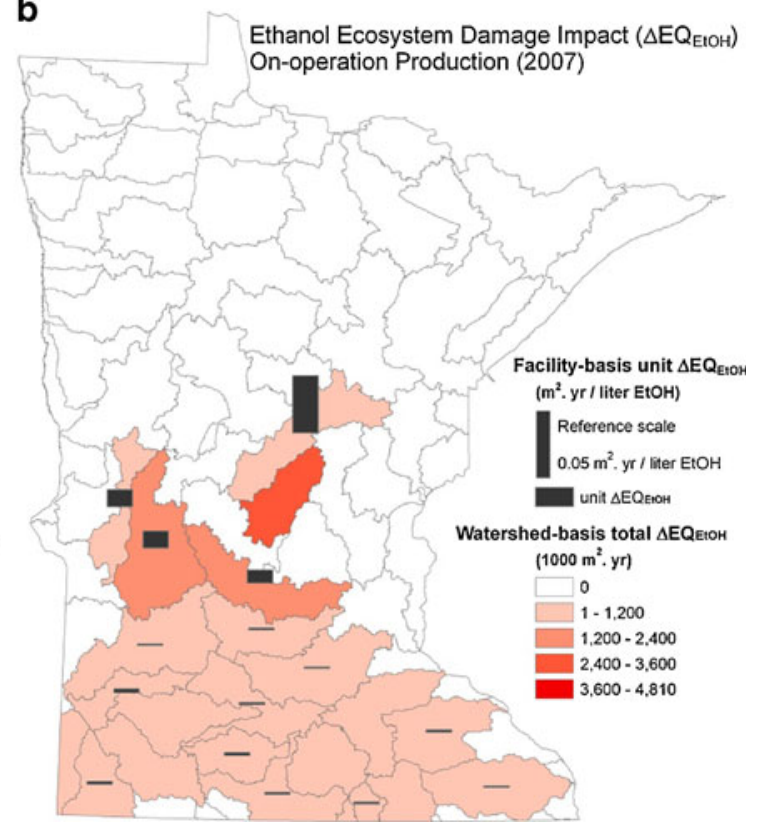

Minnesota in 2007. Bar length represents water-use impact per liter of ethanol production. Location of bars indicates watersheds with at least one ethanol conversion facility. If a watershed does not accommodate an ethanol processing facility, there is no facility-basis result associated with that watershed. Background color represents the magnitude of total ecological damage caused by corn ethanol water consumption in each watershed

\section{Discussion}

\subsection{Status quo of bioethanol production in Minnesota}

This study demonstrates the relative importance of bioethanol conversion plants' water consumption in total bioethanol's water demand. Previous studies have emphasized the importance of irrigation water consumption compared to that of bioethanol conversion plants in total embodied water in bioethanol (de Fraiture et al. 2008; National Research Council. 2008; Pimentel 2003; Pimentel and Patzek 2005). Our results show that $24 \%$ of $\Delta \mathrm{EQ}_{\mathrm{EtOH}}$

Table 1 Results of the scenarios for the planned capacity expansion in Minnesota on a watershed basis

\begin{tabular}{|c|c|c|c|c|c|}
\hline & $\begin{array}{l}\text { Total consumptive } \\
\text { water use }{ }^{\mathrm{a}}\left(\mathrm{WU}_{\mathrm{EtOH}},\right. \\
\text { billion liters) }\end{array}$ & $\begin{array}{l}\text { Total ethanol } \\
\text { production (EP, } \\
\text { billion liters) }\end{array}$ & $\begin{array}{l}\text { Total ecosystem impact } \\
\left(\Delta \mathrm{EQ}_{\mathrm{EtOH}}, \text { million }\right. \\
\left.\mathrm{m}^{2} \mathrm{yr}^{1}\right)\end{array}$ & $\begin{array}{l}\text { Specific water } \\
\text { consumption } \\
\left(\mathrm{WU}_{\mathrm{EtOH}} / \mathrm{EP}, \mathrm{LL}^{-1}\right)\end{array}$ & $\begin{array}{l}\text { Specific water-consumption } \\
\text { impact, }\left(\Delta \mathrm{EQ}_{\mathrm{EtOH}} / \mathrm{EP}\right. \\
\left.\mathrm{m}^{2} \cdot \mathrm{yrL}^{-1}\right)\end{array}$ \\
\hline $\begin{array}{l}\text { Current } \\
\text { case (as } \\
\text { of 2007) }\end{array}$ & 40 & 2.3 & 11 & 17 & 0.005 \\
\hline $\begin{array}{l}\text { As planned } \\
\text { (BAU) }\end{array}$ & 63 & 4.0 & 18 & 16 & 0.004 \\
\hline Best case & 47 & 4.0 & 13 & 12 & 0.003 \\
\hline Worst case & 112 & 4.0 & 31 & 28 & 0.008 \\
\hline
\end{tabular}

${ }^{\mathrm{a}}$ Total consumptive water use includes irrigation water consumption and process water consumption 
a

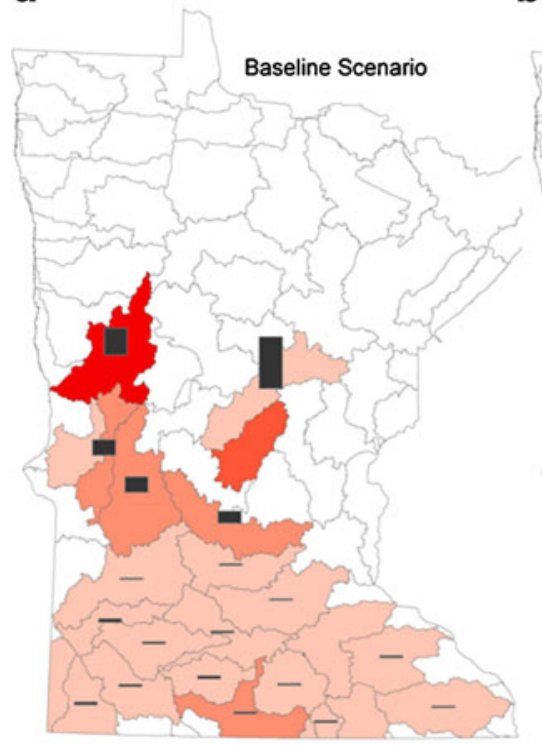

b

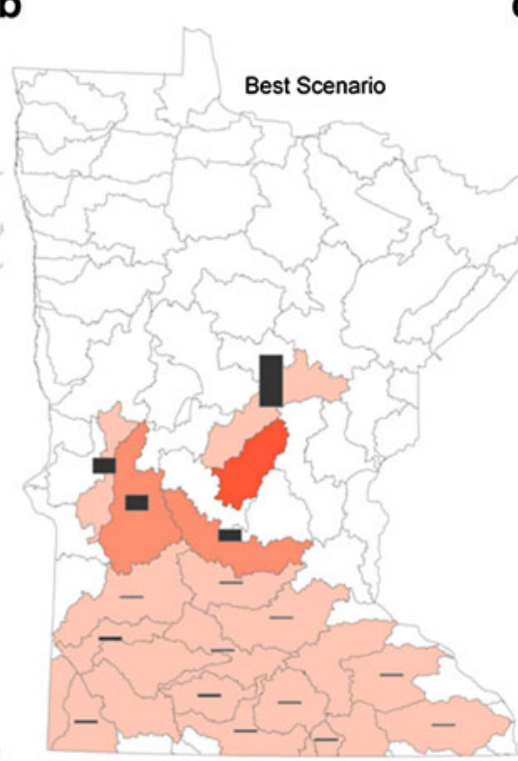

C

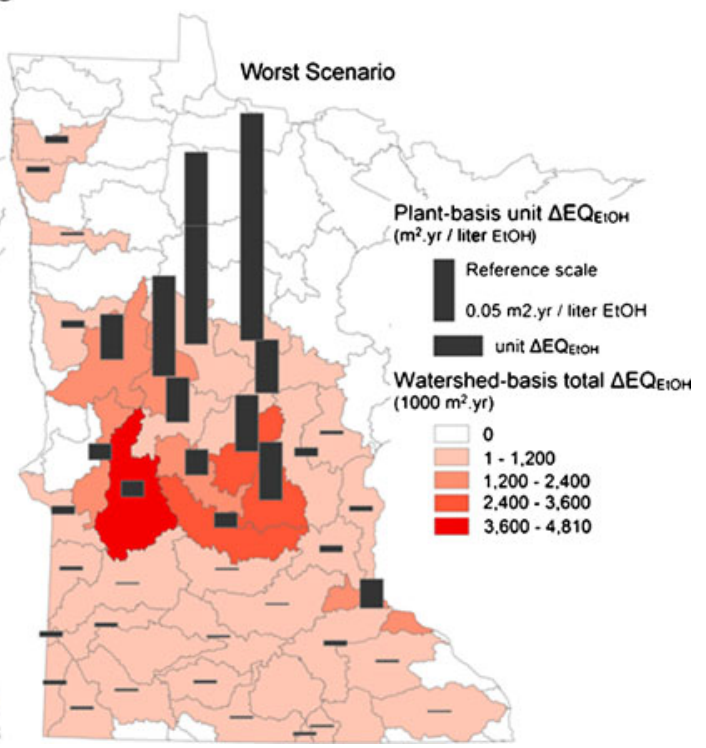

Fig. 2 Scenario analysis for long-term water-consumption impact of alternative bioethanol facility locations: a baseline scenario (plant located as planned), b best case scenario, c worst-case scenario. Background colors indicate total impact on a given watershed, and bar

was attributable to ethanol process water, and 11 out of 23 watersheds in supporting Minnesota's ethanol industry had higher process water-induced $\Delta \mathrm{EQ}_{\mathrm{EtOH}}$ than that caused by irrigation (Table S5, Electronic supplementary material). This finding indicates that water consumption for bioethanol conversion plants can be responsible for a major portion of the total bioethanol's water consumption and its associated ecological impact for some regions where the majority of corn is sourced from rain-fed cultivation.

\subsection{Modeling approach, assumptions, and sensitivities}

The results showed a significant disparity in ecological impact of water consumption between the watersheds (see Figs. 1b and 2). The significance of spatial resolution in quantifying ecological impact of water consumption has important implications to the current LCA practice. The geographical resolution of the watershed-level definitions employed in this study is much finer than the site-generic approach average LCAs generally employ. However, it might also be argued that even finer resolutions (e.g., with focus on particular groundwater aquifers) would be necessary to capture truly local specifics of water consumptionassociated environmental impacts.

From the early stage of LCA, researchers were aware of the importance of spatial differentiation in environmental impact modeling and have developed spatially differentiated characterization factors for a number of impact categories including human toxicity and acidification impacts (Hauschild 2006; Huijbregts et al. 2000; Pennington et al. length represents the impact on a per-liter bioethanol basis at watersheds where in situ ethanol plants are situated. Facility-based results are only applicable to those watersheds having ethanol plants on-site

2005; Potting et al. 2006; Potting et al. 1998). One of the key barriers of using high-resolution characterization factors is the lack of high-resolution Life Cycle Inventory data that match such characterization factors. Although water withdrawal and consumption data are being widely developed for many LCI databases, given that the water-use issue is relatively new in LCA and water scarcity is only relevant on local scale, incorporating spatial detail for such information is particularly relevant. To match the ecosystem damage assessment with the water-consumption inventory, this study represents an early example for such spatial detail, combining spatially refined characterization factors with high-resolution inventory data. It thereby goes beyond the level of recent studies combining high-resolution inventory with major watershed impact factors (Ridoutt and Pfister 2010; Pfister et al. 2011).

Following the watershed classification of Minnesota and the corresponding resolution of inventory data for bioethanol production, the newly calculated ecosystem damage factors derived from both the original damage factors and the original scale of major watershed supplied by Pfister et al. (2009) displayed a much higher spatial resolution. In contrast, the method of Milà i Canals et al. (2009) uses only one major basin for Minnesota, namely the Upper Mississippi basin, and consequently does not differentiate among different areas and smaller watersheds. The further subdivision into 81 watersheds within Minnesota was shown to be meaningful as these watersheds feature highly different climatic conditions and water abundance. This means that a surplus in one watershed might not balance out a water shortage in another, even if they share a 
physical boundary. The refined spatial resolution employed in this study enables a more accurate damage characterization, which is particularly helpful to guide future bioethanol production expansion in Minnesota.

In addition to the spatial variability, the temporal dimension of water consumption is relevant for ecosystem impacts: depending on the time in a year, the adverse effects of water consumption on the environment can be highly variable. As our method uses annual average estimates for $\mathrm{NPP}_{\text {wat-lim }}$ in the damage characterization, enhanced modeling of seasonal patterns might be useful, given that appropriate data are available, to also account for different cropping schedules in corn cultivation.

In terms of data requirements, this study used various data and assumptions with different levels of uncertainty shaping the validity and quality of the results and the conclusions drawn from them. The two most sensitive parameters, bioethanol production volume and water withdrawal for corn irrigation, were drawn from reliable government sources (U.S. Department of Agriculture. 2004; U.S. Department of Agriculture 2010), while the quality of ethanol plant's water consumption data is considered to be relatively low. Future effort can focus on refining plant water efficiency data to improve the overall quality of the result.

\subsection{Implications of future bioethanol production expansion}

The planned expansion of ethanol plants in Minnesota is expected to increase the state's ethanol production capacity by $75 \%$ and is expected to raise ecological impact due to water consumption by $64 \%$. However, strategically locating the planned expansion in the areas with lowest water-use impact is expected to contain water-consumption impact increase within 19\%. The low-impact region generally matches with high-yield and rain-fed agricultural regions, which are characterized by high precipitation and low irrigation demand. The results show that, if the distribution of ethanol water consumption impact remains the same, such regions should receive a priority for future ethanol expansion not only because of their low water requirements but also because of their low water-consumption impact.

The scenario analysis shows that, due to the significant differences in local conditions, it is important to identify the areas that might experience higher risk of water consumption impacts, which may not be properly understood by examining total water consumption figures only. In Minnesota, previous proposals for ethanol facility expansion were evaluated based on traditional environmental criteria such as waste water discharges and ground water levels. Our analysis indicates that the planned expansion in the upper western region of Minnesota may need a careful examination on water use impact given the relatively significant ecological damage that the results of this study suggest.

\section{Conclusions}

In this study, we demonstrated the application of water consumption impact assessment using the latest method proposed by Pfister et al. and quantified the ecological impact associated with corn-based bioethanol production with a spatial-explicit fashion. Though scientists may find it arguable to quantify water consumption impact solely depending on LCA characterization factors, this is by far one of the most feasible standardized approaches which can be integrated in the existing LCA framework.

If employed properly, the water consumption impact assessment can also be beneficial in supporting decision making. By using Minnesota as an example, the differences among the scenarios in ethanol production expansion reveal optimization potentials for water consumption and for reducing the associated ecological impact. Such scenario analyses are valuable for product-based assessments of bioethanol products having different supply chains by sourcing corn from differentially vulnerable watershed regions (see Table S5). In addition, water impact assessment can support regional watershed-based environmental analyses giving important implications for regional watershed management and thus assist in balancing different needs. As nearly $78 \%$ of local ethanol production was projected to be exported out of Minnesota (Minnesota Department of Agriculture 2010), the environmental costs which resulted from local water consumption would still remain in Minnesota. In the future, the scenario analysis demonstrated in this study can be applied to strategically optimize both bioethanol production and environmental savings on a national scale. Obviously, environmental impacts related to the change of plant infrastructure and agricultural practices as well as socioeconomic circumstances associated with the development of the renewable energy industry should be considered as well for identifying the most sustainable alternatives.

Acknowledgments We thank Mr. Brian Walseth of the Industrial Ecology Lab, University of Minnesota for his assistance in corn field and irrigation data acquisition. We thank Mr. Eric Fournier for his helpful comments. This research was supported in part by USDA/ CSREES and US DOE under grant number 68-3A75-7-614 and by the Legislative Citizen's Commission on Minnesota Resources.

\section{References}

Bayart JB, Bulle C, Deschenes L, Margni M, Pfister S, Vince F, Koehler A (2010) A framework for assessing off-stream freshwater use in LCA. Int J Life Cycle Assess 15(5):439-453

Bringezu S, Schütz H, O’Brien M, Kauppi L, Howarth R, McNeely J (2009) Towards sustainable production and use of resources: Assessing biofuels. International Panel for Sustainable Resources Management, UNEP, Paris 
Chiu YW, Walseth B, Suh S (2009) Water embodied in bioethanol in the United States. Environ Sci Technol 43(8):2688-2692

de Fraiture C, Giordano M, Liao Y (2008) Biofuels and implications for agricultural water use: blue impacts of green energy. Water Policy 10(S1):67-81

Environmental Protection Agency (2008a) Federal register: Renewable Fuel Standard for 2009, issued pursuant to section 211(o) of the Clean Air Act, vol 73. USEPA, Washington, DC

Environmental Protection Agency (2008b) Federal register: revised Renewable Fuel Standard for 2008, issued pursuant to section 211(o) of the Clean Air Act as amended by the Energy Independence and Security Act of 2007, vol 73. USEPA, Washington, DC

Ewing B, Reed A, Galli A, Kitzes J, Wackernagel M (2010) Calculation methodology for the national footprint accounts: 2010 edition. Global Footprint Network, Oakland, CA

Falkenmark M, Rockström J (2004) Balancing water for humans and nature: the new approach in ecohydrology. Earthscan, London

Fargione J, Hill J, Tilman D, Polasky S, Hawthorne P (2008) Land clearing and the biofuel carbon debt. Science 10(5867):1235-1238

Frischknecht R (2005) Ecoinvent data v1.1 (2004) From heterogenous databases to unified and transparent lci data. Int J Life Cycle Assess $10(1): 1-2$

GAO (2009) Energy-water nexus: many uncertainties remain about national and regional effects of increased biofuel production on water resources. Report to the Chairman, Committee on Science and Technology, House of Representatives. GAO, Washington, DC

Gerbens-Leenes W, Hoekstra AY, van der Meer TH (2009) The water footprint of bioenergy. P Natl A Sci 106(25):10219-10223

Goedkoop M, Spriensma R (2000) The Eco-Indicator 99: a damage oriented method for life cycle impact assessment (methodology report). Pré Consultants, Amersfoort

Hauschild M (2006) Spatial differentiation in life cycle impact assessment: a decade of method development to increase the environmental realism of LCIA. Int J Life Cycle Assess 11:11-13

Hoekstra AY, Chapagain AK, Aldaya MM, Mekonnen MM (2011) The water footprint assessment manual: setting the global standard. Earthscan, London

Huijbregts MAJ, Schöpp W, Verkuijlen E, Heijungs R, Reijnders L (2000) Spatially explicit characterization of acidifying and eutrophying air pollution in life-cycle assessment. J Ind Ecol 4 (3):75-92

Kim S, Dale BE (2005) Life cycle assessment of various cropping systems utilized for producing biofuels: bioethanol and biodiesel. Biomass Bioenerg 29(6):426-439

King CW, Webber ME (2008) Water intensity of transportation. Environ Sci Technol 42(21):7866-7872

Koehler A (2008) Water use in LCA: managing the planet's freshwater resources. Int J Life Cycle Assess 13(6):451-455

Milà i Canals L, Chenoweth J, Chapagain A, Orr S, Antón A, Clift R (2009) Assessing freshwater use impacts in LCA: part Iinventory modelling and characterisation factors for the main impact pathways. Int J Life Cycle Assess 14(1):28-42

Minnesota Climatology Working Group (2010) Interactively retrieve climate data. Minnesota Climatology Working Group, MN DNR. http://climate.umn.edu/. Accessed 15 Jan 2009

Minnesota Department of Agriculture (2010) Minnesota ethanol industry. MNDA. http://www.mda.state.mn.us/news/publications/ renewable/ethanol/plantsreport.pdf. Accessed 16 May 2010

Minnesota Pollution Control Agency (2007) Planning and constructing an ethanol plant in Minnesota: a guidance document. Minnesota Pollution Control Agency, St. Paul, MN

Mishra GS, Yeh S (2011) Life cycle water consumption and withdrawal requirements of ethanol from corn grain and residues. Environ Sci Technol 45(10):4563-4569
Minnesota Department of Natural Resources (2008a) Minnesota's watershed basins. MN DNR. http://www.dnr.state.mn.us/watersheds/map.html. Accessed 11 Feb 2010

Minnesota Department of Natural Resources (2008b) Water appropriations permit program. Minnesota Department of Natural Resources. http:// www.dnr.state.mn.us/waters/watermgmt_section/appropriations/ wateruse.html. Accessed 01 Sept 2009

Mohamed Y, Van Den Hurk B, Savenije H, Bastiaanssen W (2005) Hydroclimatology of the Nile: results from a regional climate model. Hydrol Earth Syst Sc 2(1):319-7364

Mubako S, Lant C (2008) Water resource requirements of corn-based ethanol. Water Resour Res 44:W00A02

National Research Council (2008) Water implications of biofuels production in the United States. National Academies Press, Washington, DC

Nebraska Energy Office (2011) Energy statistic. Nebraska Energy Office. http://www.neo.ne.gov/. Accessed 10 Jan 2011

Nemani RR, Keeling CD, Hashimoto H, Jolly WM, Piper SC, Tucker CJ, Myneni RB, Running SW (2003) Climate-driven increases in global terrestrial net primary production from 1982 to 1999. Science 300(5625):1560-1563

Patzek TW (2006) A statistical analysis of the theoretical yield of ethanol from corn starch. Nat Resour Res 15(3):205-212

Pennington DW, Margni M, Ammann C, Jolliet O (2005) Multimedia fate and human intake modeling: spatial versus nonspatial insights for chemical emissions in western Europe. Environ Sci Technol 39(4):1119-1128

Pfister S, Koehler A, Hellweg S (2009) Assessing the environmental impacts of freshwater consumption in LCA. Environ Sci Technol 43(11):4098-4104

Pfister S, Bayer P, Koehler A, Hellweg S (2011) Environmental impacts of water use in global crop production: hotspots and trade-offs with land use. Environ Sci Technol 45(13):5761-5768

Pimentel D (2003) Ethanol fuels: energy balance, economics, and environmental impacts are negative. Nat Resour Res 12(2):127-134

Pimentel D, Patzek TW (2005) Ethanol production using corn, switchgrass, and wood; biodiesel production using soybean and sunflower. Nat Resour Res 14(1):65-76

Potting J, Schöpp W, Blok K, Hauschild M (1998) Site-dependent lifecycle impact assessment of acidification. J Ind Ecol 2(2):63-87

Potting J, Hertel O, Schöpp W, Bastrup-Birk A (2006) Spatial differentiation in the characterisation of photochemical ozone formation: the EDIP2003 methodology. Int J Life Cycle Assess 11:72-80

Renewable Fuels Association (2008) Ethanol biorefinery statistics. Renewable Fuels Association. http://www.ethanolrfa.org/pages/ statistics. Accessed 10 Jan 2010

Ridoutt BG, Pfister S (2010) A revised approach to water footprinting to make transparent the impacts of consumption and production on global freshwater scarcity. Global Environ Chang 20(1):113-120

Romanow S (2007) Biofuels production in U.S. impacts water resources. Hydrocarb Process 86(12):23-725

Scown CD, Horvath A, McKone TE (2011) Water footprint of U.S. transportation fuels. Environ Sci Technol 45(7):2541-2553

Shapouri H, Duffield JA, Wang M (2003) The energy balance of corn ethanol revisited. T ASABE 46(4):959-968

Solley W, Pierce R, Perlman H (1998) Estimated use of water in the United States in 1995. US Geological Survey, Denver, CO

U.S. Department of Agriculture. (2004) 2003 farm and ranch irrigation (2002) Census of Agriculture. USDA, Washington, DC

U.S. Department of Agriculture (2010) National agricultural statistics service. USDA. http://www.nass.usda.gov/. Accessed 20 Apr 2010

Varghese S (2007) Biofuels and global water challenges. Institute for Agriculture and Trade Policy, Minneapolis

Wu M, Mintz M, Wang M, Arora S (2009) Consumptive water use in the production of ethanol and petroleum gasoline. Center for Transportation Research Energy Systems Division, Argonne National Laboratory, Lemont, IL 